\title{
The structure-property relationships in M-type hexaferrites: Hyperfine interactions and bulk magnetic properties
}

\author{
G. K. Thompson and B. J. Evans \\ Department of Chemistry, University of Michigan, Ann Arbor, Michigan 48109-1055
}

${ }^{57} \mathrm{Fe}$ Mössbauer spectroscopic measurements have been made at $296 \mathrm{~K}$ on single crystals of $\mathrm{MFe}_{12} \mathrm{O}_{19}(\mathrm{M}=\mathrm{Ba}, \mathrm{Sr}, \mathrm{Pb})$ oriented parallel and perpendicular to the $c$ axis, permitting the establishment of the systematics of the static and dynamical aspects of the hyperfine interactions, and their relationship to crystal/chemical structures for the five $\mathrm{Fe}^{3+}$ sublattices, and to the bulk magnetic properties. With the exception of the electric quadrupole interaction at the $2 b$ site, and the dependence of the $2 b$ intensity on the crystal orientation, the magnitude of the hyperfine interactions of a given $\mathrm{Fe}^{3+}$ site exhibits only small variations among the different hexaferrites. The magnitude of the quadrupole interaction at the $2 b$ site varies by more than $10 \%$, with the $2 b$ site in $\mathrm{PbFe}_{12} \mathrm{O}_{19}$ exhibiting the smallest value. The relative intensity of the $2 b$ subspectrum varies markedly among the three hexaferrites for observations parallel and perpendicular to the $c$ axis. Although all display the expected anisotropy resulting from the libration of the $2 b \mathrm{Fe}^{3+}$ parallel to the $c$ axis, the anisotropy is considerably larger for $\mathrm{PbFe}_{12} \mathrm{O}_{19}$ than for $\mathrm{BaFe}_{12} \mathrm{O}_{19}$ or $\mathrm{SrFe}_{12} \mathrm{O}_{1 \%}$. It is remarkable that the bulk magnetic anisotropy follows the same order as the anisotropy in the dynamical displacement and crystalline electric field of the $2 b$ site.

\section{INTRODUCTION}

The M-type hexaferrites, $\mathrm{MFe}_{12} \mathrm{O}_{19}(\mathrm{M}=\mathrm{Ba}, \mathrm{Sr}, \mathrm{Pb})$, are an important class of ferrimagnetic oxides. Their magnetic properties make them excellent materials for use as permanent magnets, recording media, and as components in microwave and higher-frequency devices.

The structure of these ferrites may be considered to consist of alternating spinel $\left(\mathrm{S}=\mathrm{Fe}_{6} \mathrm{O}_{8}^{2+}\right)$ and hexagonal ( $\mathrm{R}=\mathrm{MFe} \mathrm{e}_{6} \mathrm{O}_{11}^{2}$ ) layers. The $\mathrm{O}^{2-}$ ions exist as closepacked layers, with the $\mathrm{M}^{2+}$ substituting for an $\mathrm{O}^{2-}$ in the hexagonal layer. The $\mathrm{Fe}^{3+}$ ions are distributed in the interstitial spaces of the close packed layers. Three of the $\mathrm{Fe}^{3+}$ sites are octahedral $\left(12 k, 4 f_{2}\right.$, and $\left.2 a\right)$; one is tetrahedral $\left(4 f_{1}\right)$, and one is trigonal bipyramidal $(2 b)$.

In previous investigations, single-crystal ${ }^{57} \mathrm{Fe}$ Mössbauer spectroscopy and $\mathrm{x}$-ray diffraction measurements were employed to investigate the dynamics of the $2 b \mathrm{Fe}^{3+}$ ion in $\mathrm{BaFe}_{12} \mathrm{O}_{19}$ (Refs. 1-5), $\mathrm{SrFe}_{12} \mathrm{O}_{19}$ (Refs. 3, 6-8), and $\mathrm{PbFe}_{12} \mathrm{O}_{19} \cdot{ }^{9,10}$ However, quantitative and comparative data on the vibrational anisotropy of all the $\mathrm{Fe}^{3+}$ ions in the end-member hexaferrites, and on their respective hyperfine interaction parameters have been lacking.

Therefore, to determine what influence each of the five $\mathrm{Fe}^{3+}$ sites has on the bulk magnetic properties of the different $\mathrm{MFe}_{12} \mathrm{O}_{19}$ compounds, Mössbauer spcctra have been obtained at $296 \mathrm{~K}$ for single crystals with the $c$ axis parallel and perpendicular to the $\gamma$-ray propagation direction.

\section{Il. EXPERIMENT}

${ }^{57} \mathrm{Fe}$ Mössbauer spectra were collected at $296 \mathrm{~K}$ for oriented single crystals of $\mathrm{BaMn}_{0.3} \mathrm{Fe}_{11.7} \mathrm{O}_{19}, \mathrm{SrFe}_{12} \mathrm{O}_{19}$, and $\mathrm{PbFe}_{12} \mathrm{O}_{19}$. The resulting hyperfine parameters have been compared with the parameters of polycrystalline $\mathrm{BaFe}_{12} \mathrm{O}_{19}, \mathrm{SrFe}_{12} \mathrm{O}_{19}$, and $\mathrm{PbFe}_{12} \mathrm{O}_{19}$ reported in an earlier study from this laboratory. ${ }^{10}$ The spectra were obtained and analyzed as described in detail in a previous report." Electron microprobe analysis (EMPA) and x-ray powder diffraction were employed to determine the composition and purity of the samples.

\section{RESULTS AND DISCUSSION}

The spectra for the case in which the $c$ axis is perpendicular to the $\gamma$-ray propagation direction are quite similar for all samples. A typical spectrum for this orientation, that of $\mathrm{SrFe}_{12} \mathrm{O}_{19}$, is shown in Fig. 1, along with the spectrum of a polycrystalline sample for comparison. The hyperfine parameters of all the single-crystal samples are listed in Tables I-III. In this orientation, except for $\mathrm{SrFe}_{12} \mathrm{O}_{19}$, the relative intensity of the $2 b$ subspectrum for each of the samples is fairly close to the theoretical value of 2 , where the $12 k$ site has a normalized intensity of 12 (Tables I-III). For a given $\mathrm{Fe}^{3+}$ site, the hyperfinc parameters exhibit, with few exceptions, no significant variations between the hexaferrites.

The first exception is the unusually large isomer shift of the $2 a$ subspectrum of $\mathrm{SrFe}_{12} \mathrm{O}_{19}$, relative to the other hexaferrites (Tables I-III). This deviation may be due to the difficulty in resolving the $4 f_{1}$ and $2 a$ components. The second exception is in the high values of the quadrupole interaction of the $4 f_{1}$ and $2 a$ sites in $\mathrm{BaMn}_{0.3} \mathrm{Fe}_{11.7} \mathrm{O}_{19}$ (Fig. 2). These larger than normal quadrupole interactions may be due to Jahn-Teller distortions, which have been observed in polycrystalline $\mathrm{BaMn}_{x} \mathrm{Fe}_{12-x} \mathrm{O}_{19 .}{ }^{12}$

It is notable that, except for the $2 b$ site, the electric quadrupole interactions in $\mathrm{SrFe}_{12} \mathrm{O}_{19}$ and $\mathrm{PbFe}_{12} \mathrm{O}_{19}$ are very similar for all the iron sites. The quadrupole interaction for the $2 b$ site in $\mathrm{SrFe}_{12} \mathrm{O}_{19}$ is $2.28 \mathrm{~mm} \mathrm{~s}^{-1}$, versus 2.00 $\mathrm{mm} \mathrm{s}^{-1}$ for $\mathrm{PbFe}_{12} \mathrm{O}_{19}$. A comparison of the electric quad- 


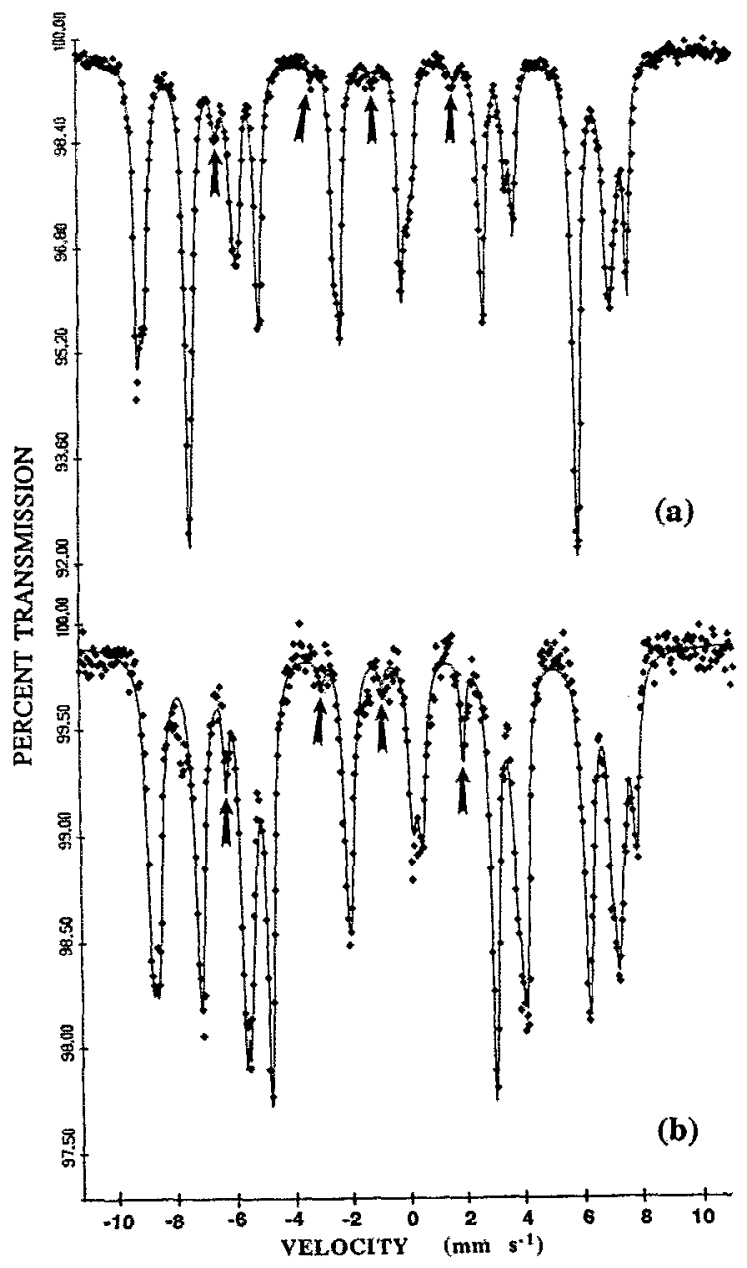

FIG. 1. (a) ${ }^{57} \mathrm{Fe}$ Mössbauer spectrum of polycrystalline $\mathrm{SrFe}_{12} \mathrm{O}_{19}$ at 296 K. (b) ${ }^{57} \mathrm{Fe}$ Mössbauer spectrum of single-crystal $\mathrm{SrFe}_{12} \mathrm{O}_{19}$ ( $c$ axis perpendicular to $\gamma$-ray beam) at $296 \mathrm{~K}$. Arrows in (a) and (b) indicate the $2 b$ subspectrum.

TABLE 1. ${ }^{57} \mathrm{Fe}$ hyperfine parameters for single-crystal $\mathrm{PbFe}_{12} \mathrm{O}_{19}$ at 296 K.

\begin{tabular}{lccccc}
\hline \hline $\begin{array}{l}\mathrm{Fe}^{3+} \\
\text { site }\end{array}$ & $\begin{array}{c}\text { Crystal } \\
\text { alignment }\end{array}$ & $\begin{array}{c}H_{\text {eff }}{ }^{\mathrm{a}} \\
(\mathrm{kOe})\end{array}$ & $\begin{array}{c}\Delta^{\mathrm{a}} \\
\left(\mathrm{mm} \mathrm{s}^{-1}\right)\end{array}$ & $\begin{array}{c}\delta^{\mathrm{a}} \\
\left(\mathrm{mm} \mathrm{s}^{-1}\right)\end{array}$ & $\begin{array}{c}\text { Relative } \\
\text { intensity }\end{array}$ \\
\hline \multirow{2}{*}{$4 f_{2}$} & $c \perp \gamma$-ray & 412 & 0.35 & 0.33 & 12 \\
& $c \| \gamma$-ray & 414 & 0.35 & 0.35 & 12 \\
$4 f_{1}$ & $c \perp \gamma$-ray & 513 & 0.29 & 0.39 & 4.9 \\
& $c \perp \gamma$-ray & 517 & 0.34 & 0.39 & 5.3 \\
$2 a$ & $c \|$-ray & 494 & 0.11 & 0.30 & 4.4 \\
& $c \perp \gamma$-ray & 490 & 0.15 & 0.26 & 7.3 \\
$2 b$ & $c \| \gamma \gamma$-ray & 486 & 0.13 & 0.24 & 3.8 \\
& $c \perp \gamma$-ray & 398 & 2.00 & 0.30 & 2.2 \\
& $c \|$-ray & 415 & 2.45 & 0.43 & 0.9 \\
\hline
\end{tabular}

"Estimated errors in $H_{\text {eff, }} \Delta$, and $\delta$ (relative to $\mathrm{Fe}$ metal) are $\pm 1 \mathrm{kOe}$, $\pm 0.02 \mathrm{~mm} \mathrm{~s}^{-1}$, and $\pm 0.01 \mathrm{~mm} \mathrm{~s}^{1}$, respectively.
TABLE II. ${ }^{57} \mathrm{Fe}$ hyperfine parameters for single-crystal $\mathrm{SrFe}_{12} \mathrm{O}_{19}$ at 296 K.

\begin{tabular}{lccccc}
\hline \hline $\begin{array}{l}\mathrm{Fe}^{3+} \\
\text { site }\end{array}$ & $\begin{array}{c}\text { Crystal } \\
\text { alignment }\end{array}$ & $\begin{array}{c}H_{\mathrm{eff}}{ }^{2} \\
(\mathrm{kOe})\end{array}$ & $\begin{array}{c}\Delta^{\mathrm{a}} \\
\left(\mathrm{mm} \mathrm{s}^{-1}\right)\end{array}$ & $\begin{array}{c}\delta^{\mathrm{a}} \\
\left(\mathrm{mm} \mathrm{s} \mathrm{s}^{-1}\right)\end{array}$ & $\begin{array}{c}\text { Relative } \\
\text { intensity }\end{array}$ \\
\hline $12 k$ & $c \perp \gamma$-ray & 411 & 0.42 & 0.36 & 12 \\
& $c \| \gamma \gamma$-ray & 410 & 0.51 & 0.34 & 12 \\
$4 f_{2}$ & $c 1 \gamma$-ray & 515 & 0.28 & 0.41 & 5.8 \\
& $c \| \gamma$-ray & 511 & 0.57 & 0.43 & 4.9 \\
$4 f_{1}$ & $c 1 \gamma$-ray & 487 & 0.12 & 0.30 & 9.1 \\
& $c \| \gamma$-ray & 503 & 0.47 & 0.28 & 4.1 \\
$2 a$ & $c 1 \gamma$-ray & 501 & 0.13 & 0.34 & 2.2 \\
& $c \| \gamma$-ray & 494 & 0.24 & 0.38 & 2.1 \\
$2 b$ & $c \perp \gamma$-ray & 407 & 2.28 & 0.27 & 3.4 \\
& $c \| \gamma$-ray & 412 & $0.95^{\mathrm{b}}$ & $1.03^{\mathrm{b}}$ & 1.7 \\
\hline \hline
\end{tabular}

${ }^{2}$ Estimated errors in $H_{\text {eifi }} \Delta$, and $\delta$ (relative to Fe metal) are $\pm 0.0 \mathrm{kOe}$, $\pm 0.02 \mathrm{~mm} \mathrm{~s}^{-1}$, and $\pm 0.01 \mathrm{~mm} \mathrm{~s}^{-1}$, respectively.

${ }^{b}$ Due to the absence of the number 2 and 5 lines, these values are suspect.

rupole interaction in $\mathrm{BaFe}_{12} \mathrm{O}_{19}$ with that in $\mathrm{SrFe}_{12} \mathrm{O}_{19}$ and $\mathrm{PbFe}_{12} \mathrm{O}_{19}$ is problematic, due to the absence of crystal data. However, it is clear that the intrinsic quadrupole splitting for $\mathrm{SrFe}_{12} \mathrm{O}_{19}$ and $\mathrm{BaFe}_{12} \mathrm{O}_{19}$ are quite similar, based on the similarity of the apparent values of the polycrystalline samples: 2.27 and $2.30 \mathrm{~mm} \mathrm{~s}^{-1}$ for $\mathrm{SrFe}_{12} \mathrm{O}_{19}$ and $\mathrm{BaFe}_{12} \mathrm{O}_{19}$, respectively. ${ }^{10}$

Because the values of the apparent quadrupole interaction for the polycrystalline $\mathrm{MFe}_{12} \mathrm{O}_{19}$ samples are quite close to the intrinsic values for the crystals, it is clear that $H_{\text {eff }}$ and the electric field gradient are collinear, as expected.

When the $c$ axis is parallel to the $\gamma$-ray propagation direction, there are noticeable differences between the spectra of the different hexaferrites (Fig. 3). Although Mössbauer spectra of $\mathrm{MFe}_{12} \mathrm{O}_{19}$ in this orientation have been

TABLE III. ${ }^{57} \mathrm{Fe}$ hyperfine parameters for single-crystal $\mathrm{BaMn}_{0.3} \mathrm{Fe}_{1.7} \mathrm{O}_{19}$ at $296 \mathrm{~K}$.

\begin{tabular}{|c|c|c|c|c|c|}
\hline $\begin{array}{l}\mathrm{Fe}^{3+} \\
\text { site }\end{array}$ & $\begin{array}{c}\text { Crystal } \\
\text { alignment }\end{array}$ & $\begin{array}{c}H_{\mathrm{eff}}^{\mathrm{a}} \\
(\mathrm{kOe})\end{array}$ & $\begin{array}{c}\Delta^{\mathrm{a}} \\
\left(\mathrm{mm} \mathrm{s}^{-1}\right)\end{array}$ & $\begin{array}{c}\delta^{\mathrm{a}} \\
\left(\mathrm{mms}^{-1}\right)\end{array}$ & $\begin{array}{l}\text { Relative } \\
\text { intensity }\end{array}$ \\
\hline \multirow[t]{2}{*}{$12 k$} & $c \perp \quad \gamma$-ray & 413 & 0.47 & 0.38 & 12 \\
\hline & $c \| \gamma$-ray & 411 & 0.52 & 0.36 & 12 \\
\hline \multirow[t]{2}{*}{$4 f_{2}$} & $c \perp \gamma$-ray & 508 & 0.35 & 0.50 & 5.5 \\
\hline & $c \| \gamma$-ray & 509 & 0.48 & 0.44 & 5.8 \\
\hline \multirow[t]{2}{*}{$4 f_{1}$} & $c \perp \gamma$-ray & 482 & 0.53 & 0.25 & 4.7 \\
\hline & $c \| \gamma-\mathrm{ray}$ & 485 & 0.45 & 0.30 & 7.1 \\
\hline \multirow[t]{2}{*}{$2 a$} & $c \perp \gamma$-ray & 497 & 0.37 & 0.31 & 3.1 \\
\hline & $c \| \gamma$-ray & 503 & 0.20 & 0.43 & 3.6 \\
\hline \multirow[t]{2}{*}{$2 b$} & $c \perp \gamma$-ray & 402 & 2.29 & 0.31 & 2.1 \\
\hline & $c \| \gamma$-ray & $\ldots$ & $\cdots$ & $\ldots$ & 0 \\
\hline
\end{tabular}

${ }^{2}$ Estimated errors in $H_{\mathrm{eff}}, \Delta$, and $\delta$ (relative to $\mathrm{Fe}$ metal) are $\pm 2 \mathrm{kOe}$, $\pm 0.02 \mathrm{~mm} \mathrm{~s}^{-1}$, and $\pm 0.01 \mathrm{~mm} \mathrm{~s}^{1}$, respectively. 


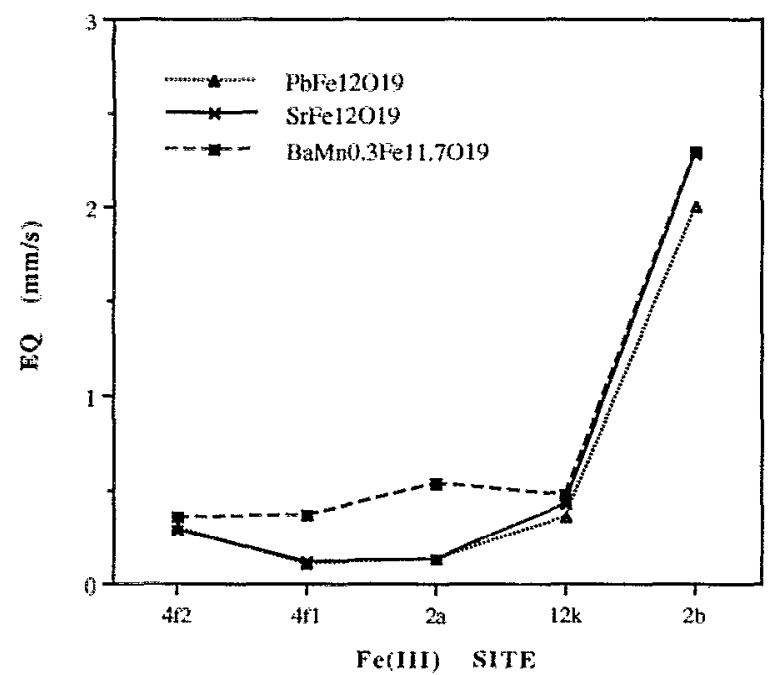

FIG. 2. Plot of $\mathrm{Fe}^{3+}$ site vs quadrupole interaction for $\mathrm{MFe}_{12} \mathrm{O}_{19}$ at 296 $\mathrm{K}$ ( $c$ axis perpendicular to $\gamma$-ray beam).

collected before, only now have quantitative differences been observed between the hexaferrites. It had previously been assumed that the hexaferrites exhibited similar anisotropies.

As is evident in Tables I and II, the relative intensity of the $2 b$ subspectrum is clearly greater in $\mathrm{SrFe}_{12} \mathrm{O}_{19}$ than in $\mathrm{PbFe}_{12} \mathrm{O}_{19}$. This smaller relative intensity indicates that the $2 b \mathrm{Fe}^{3+}$ ion exhibits a significantly greater displacement parallel to the $c$ axis in $\mathrm{PbFe}_{12} \mathrm{O}_{19}$ than in $\mathrm{SrFe}_{12} \mathrm{O}_{19}$. For the $\mathrm{BaMn}_{0.3} \mathrm{Fe}_{11.7} \mathrm{O}_{19}$ crystal, the low signal-to-noise ratio of the spectrum prevents any conclusions from being drawn about the displacement of the $2 b \mathrm{Fe}^{3+}$ ion in $\mathrm{BaFe}_{12} \mathrm{O}_{19}$. But based on the relative intensity of the $2 b$ subspectra in the polycrystalline and perpendicularly oriented $\mathrm{MFe}_{12} \mathrm{O}_{19}$ samples, the $2 b \mathrm{Fe}^{3+}$ vibrational anisotropy of $\mathrm{BaFe}_{12} \mathrm{O}_{19}$ is expected to be very similar to that of $\mathrm{SrFe}_{12} \mathrm{O}_{19}$.

\section{CONCLUSION}

Analysis of the ${ }^{57} \mathrm{Fe}$ Mössbauer hyperfine parameters for oriented single crystals have allowed the submicroscopic structure of the M-type hexaferrites to be related to their bulk magnetic properties. Only the $2 b$ quadrupole interaction varies significantly between the three hexaferrites, suggesting that the oscillation parallel to the $c$ axis of the $2 b \mathrm{Fe}^{3+}$ ion is the most important factor in determining the differences in their bulk magnetic hehavior.

Based on the relative intensities of the $2 b$ subspectra for crystals with the $c$ axis parallel to the $\gamma$ ray, a tentative ranking of the anisotropy in the displacement of the $2 b$ $\mathrm{Fe}^{3+}$ ion in the $\mathrm{MFe}_{12} \mathrm{O}_{19}$ group can be inferred: $\mathrm{PbFe}_{12} \mathrm{O}_{19}>\mathrm{SrFe}_{12} \mathrm{O}_{19} \approx \mathrm{BaFe}_{12} \mathrm{O}_{19}$.

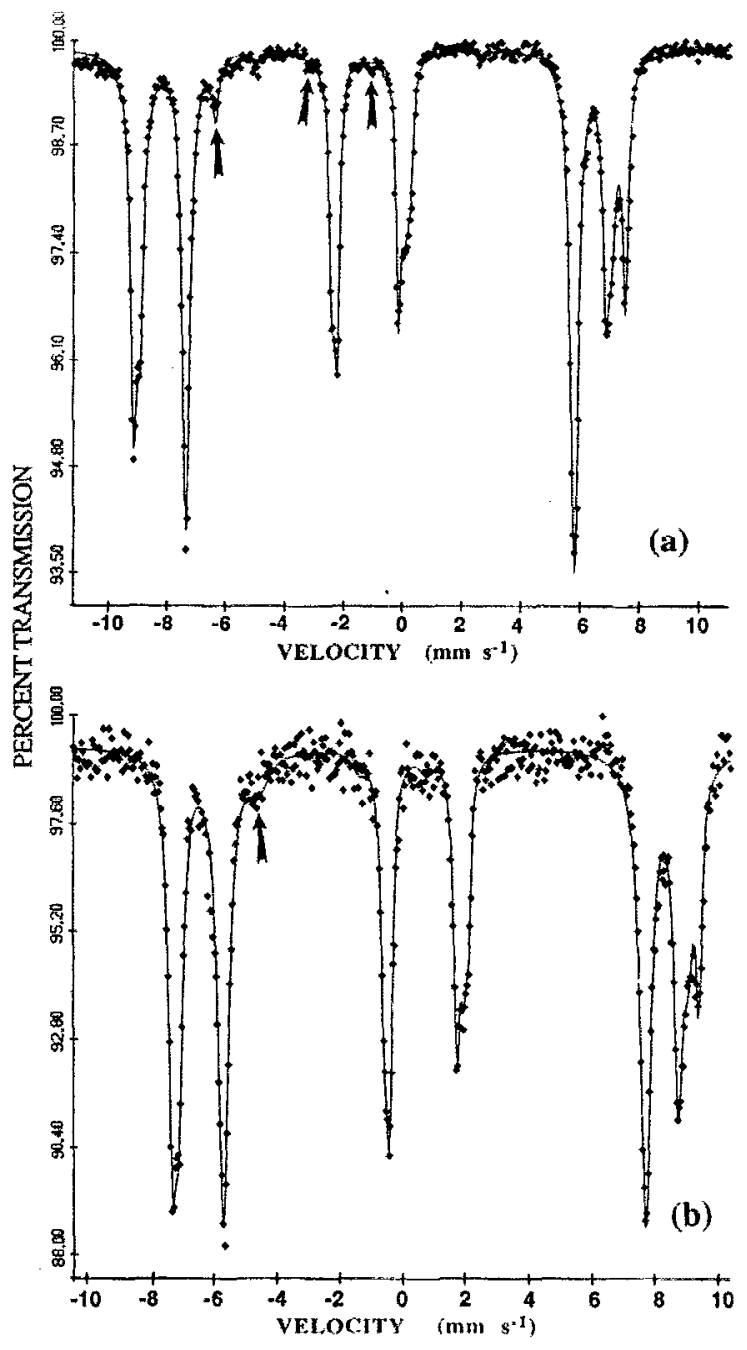

FIG. 3. (a) ${ }^{57} \mathrm{Fe}$ Mössbauer spectrum of single-crystal $\mathrm{SrFe}_{12} \mathrm{O}_{19}$ ( $c$ axis parallel to $\gamma$-ray beam) at $296 \mathrm{~K}$. (b) ${ }^{57} \mathrm{Fe}$ Mössbauer spectrum of singlecrystal $\mathrm{PbFe}_{12} \mathrm{O}_{19}$ (c axis parallel to $\gamma$-ray beam) at $296 \mathrm{~K}$. Arrows in (a) and $(\mathrm{b})$ indicate the $2 b$ subspectrum.

${ }^{1}$ J. G. Rensen and J. S. van Wieringen, Solid State Commun. 7, 1139 (1969).

${ }^{2}$ E. Kreber, U. Gonser, A. Trautwein, and F. E. Harris, J. Phys. Chem. Solids 36, 263 (1975).

${ }^{3}$ Y. U. Mamalui, V. P. Romanov, and K. M. Matsievskii, Sov. Phys. Solid State 21, 117 (1979).

${ }^{4} \mathrm{X}$. Obradors, A. Isalguè, J. Rodríguez, and J. Tejada, Cryst. Lattice Defects Amorph. Mater. 16, 31 (1987).

${ }^{5} \mathrm{~J}$. Fontcuberta, A. Isalgué, and X. Obradors, Z. Phys. B: Condensed Matter 70, 379 (1988).

${ }^{6} \mathrm{~J}$. Fonteuberta and X. Obradors, J. Phys. C: 21, 2335 (1988).

${ }^{7}$ K. Kimura, M. Ohgaki, K. Tanaka, H. Morikawa, and F. Marumo, J. Solid State Chem. 87, 186 (1990).

${ }^{8} J$ J. Muller and A. Collomb, J. Magn. Magn. Mater. 103, 194 (1992).

${ }^{9} \mathrm{~L}$. Jizhe, $Z$. Yuchang, J. Hongzhen, and Z. Hongru, Kexue Tongbao 25, 388 (1980).

${ }^{10} \mathrm{G}$. Thompson and B. Evans, J. Magn. Magn. Mater. 95, L142 (1991).

${ }^{11}$ B. J. Evans, F. Grandjean, A. P. Lilot, R. II. Vogel, and A. Gérard, J. Magn. Magn. Mater. 67, 123 (1987).

${ }^{12}$ X. Obradors, A. Collomb, M. Pernet, and J. C. Joubert, J. Magn. Magn. Mater. 44, 118 (1984). 